BANGLADESH J CHILD HEALTH 2010; VOL 34 (3): 118-121

\title{
A Family With Marfanoid Features and Cardiac Anomaly Inconsistent with Marfan Syndrome
}

\author{
M NURULABSAR ${ }^{1}$, MD. IQBAL HOSSAIN ${ }^{2}$, MOSTOFA ZAMAN ${ }^{3}$
}

\section{Introduction:}

Marfan syndrome is a genetic disorder inherited in autosomal dominant way. Predominant involvement occurs in eye, cardiovascular system and skeletone ${ }^{1}$. Main pathological lesion is defective formation of collagen tissue, i.e., fibrillin- $-^{2-4}$. Predominant cardiac lesions are aortic and mitral valve disease and dissection of aorta $3,5,6$. Tall and slender limb bones, dislocation of lense and laxity of joints are remarkable features ${ }^{3,7}$. There is no report of endocardial cushion defect or single atrium. Neither is there any report of situs inversus, dextro cardia or any renal anomaly. We are presenting an index case with other affected members of family who have major features of Marfan Syndrome. All of the above mentioned cardiac features are unique in our reported case.

Key wards: Marfan syndrome, Cardiac anomaly, Cyanotic heart disease, Autosomal dominant.

\section{Case Report}

A 10 years old boy was admitted in Rangpur Medical College Hospital on 30. 05. 09. His main complaints were gradual deformity of the trunk and chest, which was noticed by parents for last 5 years and long and slender limbs compared to his peers. The mother of the child stated that her child was as like as other normal children up to the age of 5 years. Since then his trunk started bending gradually towards right. She also noticed gradual deformity of the chest increasing day by day. His limbs also looked long and slender. Moreover, he used to become tired easily when playing outdoor games with the other children. Mother can recall the fact that the child used to become bluish during crying and exertion at the period of infancy. During infancy the child also used to have repeated respiratory infections. The child has one younger brother and one younger sister. His younger brother is now 5 yeas old and he, as per statement of the mother started tracking the same path as his elder brother. He is having dyspnoea on playing and started bending like his brother. "His limbs are also slender and long", mother states. Father of the child is also tall and has the slender limbs, although he is in good health otherwise.

The child was examined meticulously. The child had long face with central and peripheral clubbing in all fingers and toes. BP was $90 / 50 \mathrm{~mm}$ of $\mathrm{Hg}$. Pulse-80/ min and respiratory rate was $28 / \mathrm{min}$. His height was $141 \mathrm{~cm}$ (HAZ: +1.4SD) and weight was $22 \mathrm{~kg}$ (WAZ: 2.3SD). Total arm span was $143 \mathrm{~cm}$. Arm span to height ratio was 1.02:1. Upper segment to lower segment ratio was 1:1.203 (Fig.-1,2). He had high arched palate with mal-occlusion of teeth (Fig.-3).

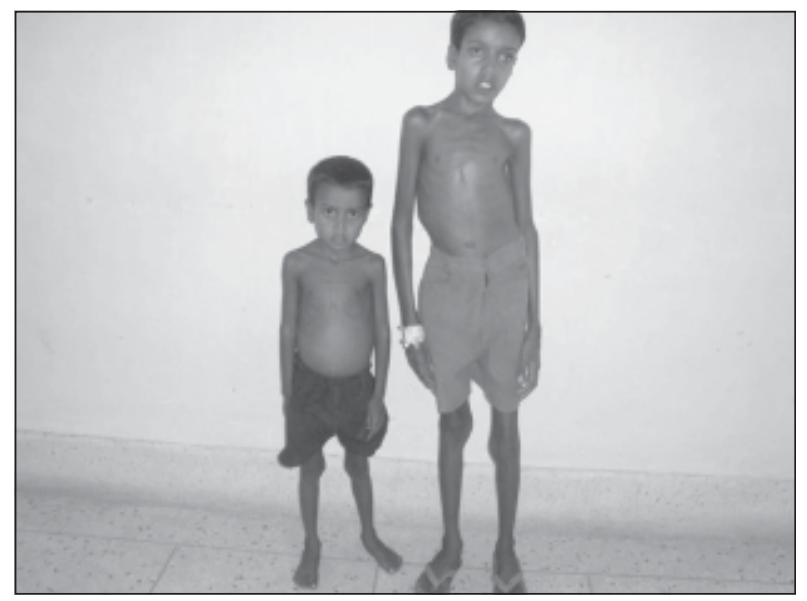

Fig.-1: Two brothers with Marfan syndrome

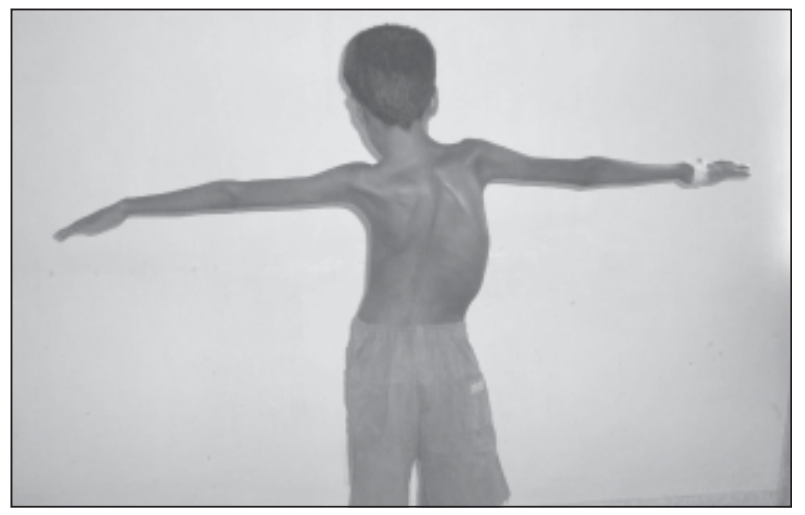

Fig.-2: Long arm span \& scoliosis

1. Professor of Paediatrics, Rangpur Medical College, Rangpur

2. Medical Officer, Department of Paediatrics, Rangpur Medical College, Rangpur

3. Medical Officer, Department of Paediatrics, Rangpur Medical College, Rangpur

Correspondence: Dr. M Nurul Absar 


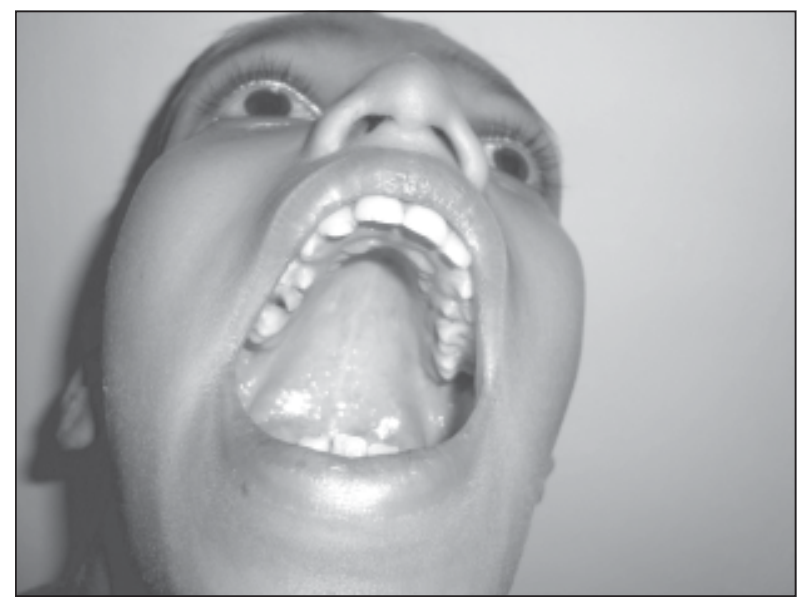

Fig.-3: High arched palate

The child had visual ascquity (VA), Right eye: 6/6, Left eye: 6/9. The child was myopic and had atrophy of dilator pupillae muscles and faint opacity of left cornea. Lense and cornia was normal. Fundus oculi was normal.

He had long and slender upper limbs with long and slender fingers with clubbing. Hyperextensibility of thumb was present. Sternberg sign and wrist sign was positive (Fig.-4,5,6,7). Lower limbs were long and slender with long and slender toes with clubbing present and overriding of $2^{\text {nd }}$ and $3^{\text {rd }}$ toes were remarkable. Marked scoliosis to right and grossly

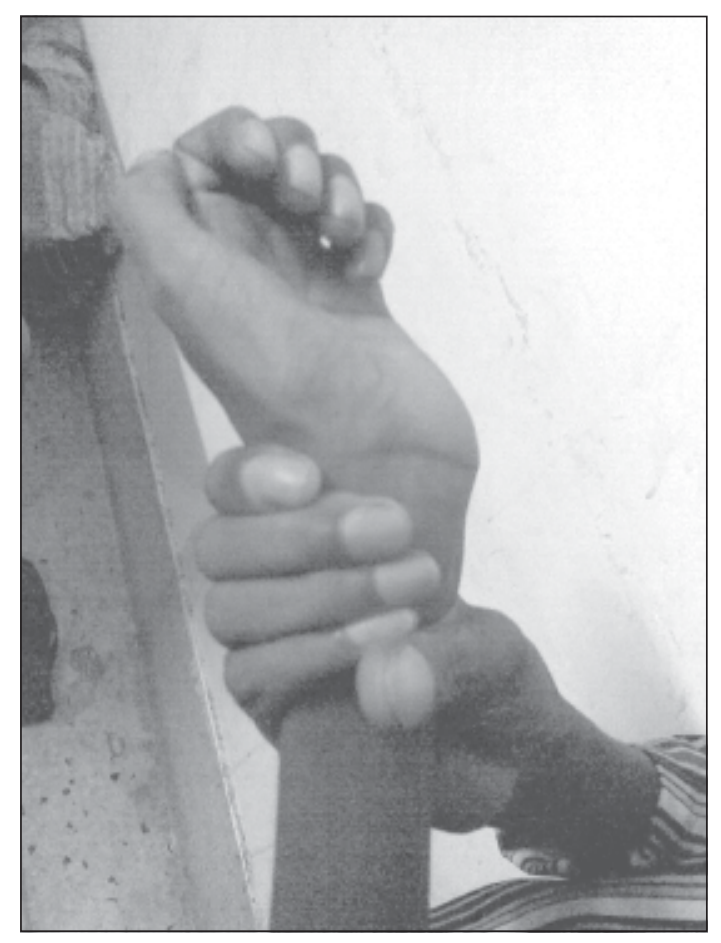

Fig.-4: Wrist sign

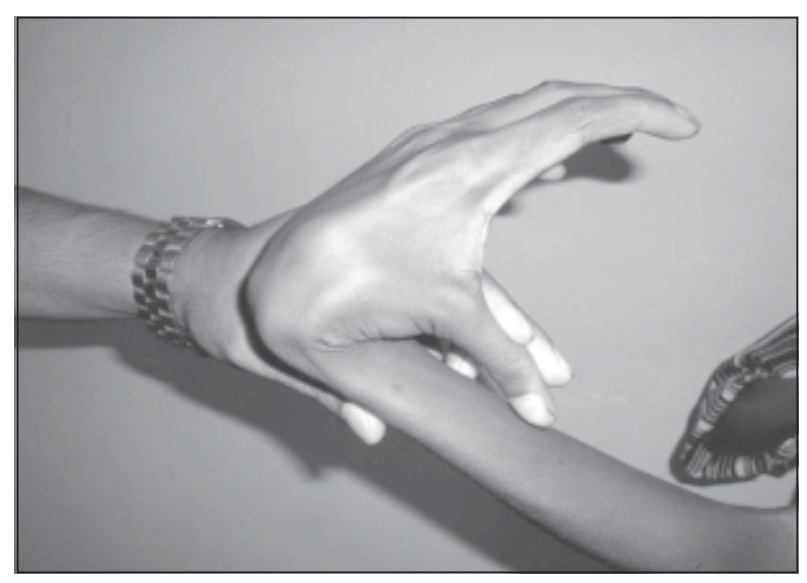

Fig.-5: Laxity of wrist joint

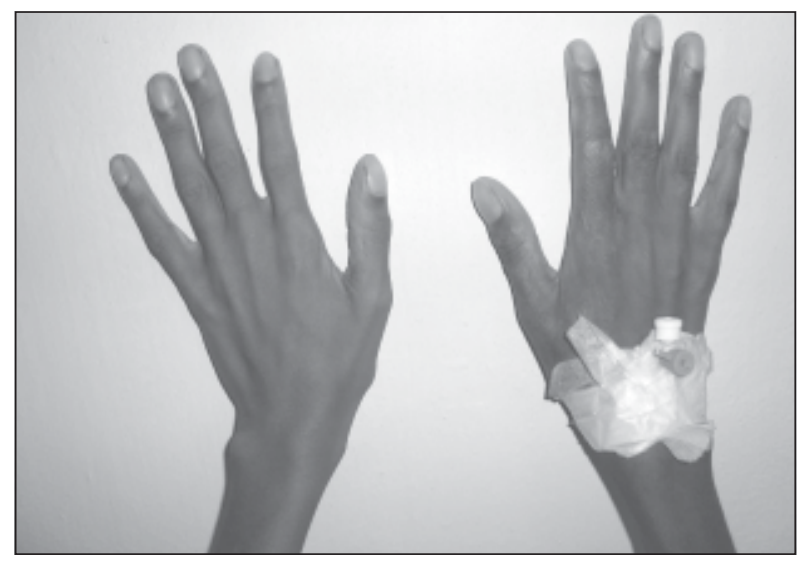

Fig.-6: Fingers with cyanosis \& clubbing

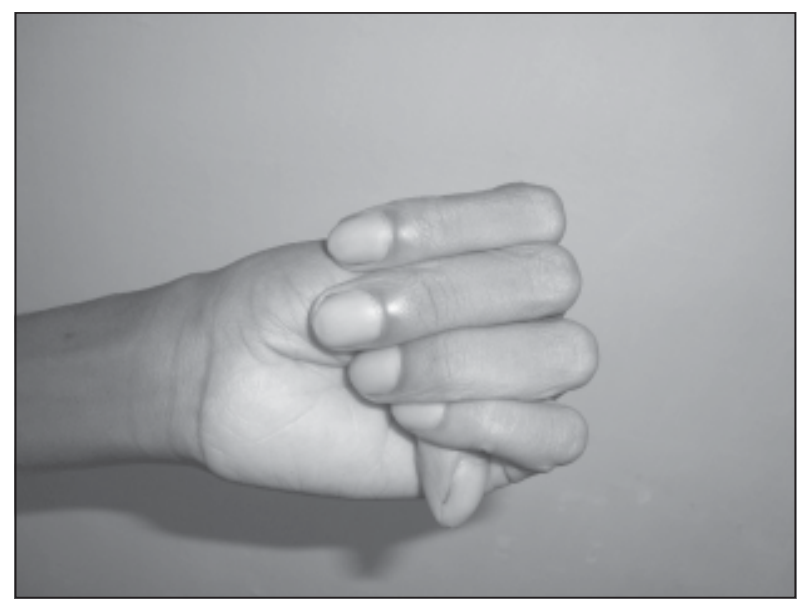

Fig.-7: Sternberg sign

deformed chest case were noted (Fig.-2). Total arm span and arm span to height ratio were increased (noted earlier). Upper segment to lower segment ratio was decreased (noted earlier). Pectus carinatum was present. Apex beat was shifted to left. Audible systolic murmur was present in parasternal area. No significant abnormality was found in any other system. 
Investigation revealed that there was dorso-lumber scoliosis (Fig.-8). It was $50^{\circ}$ in dorsal spine and $30^{\circ}$ in lumber spine. Phalanges and metacarpals were long and slender (Fig.-9). Echo cardiography showed complete AV canal defect. Ultrasound of abdomen revealed situs inversus with calyceal dilatation of left kidney with a cyst within it.

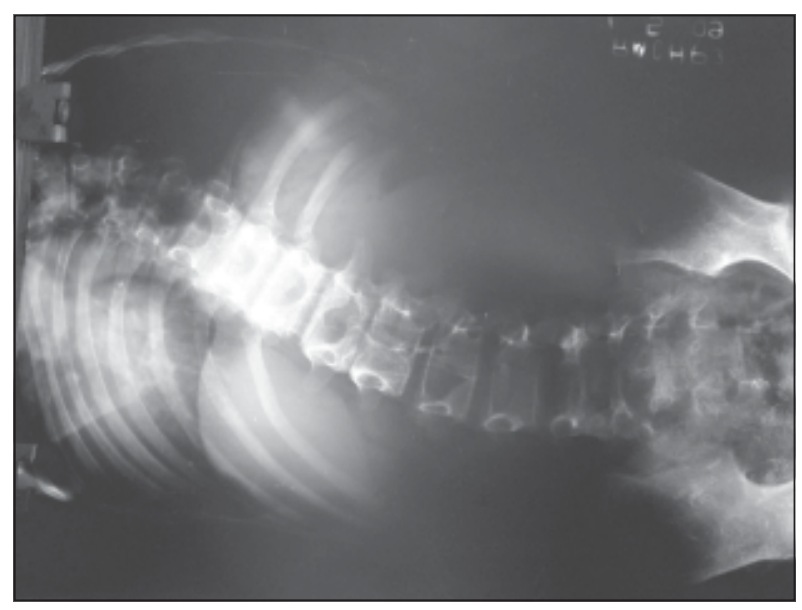

Fig.-8: Dorsolumber scoliosis

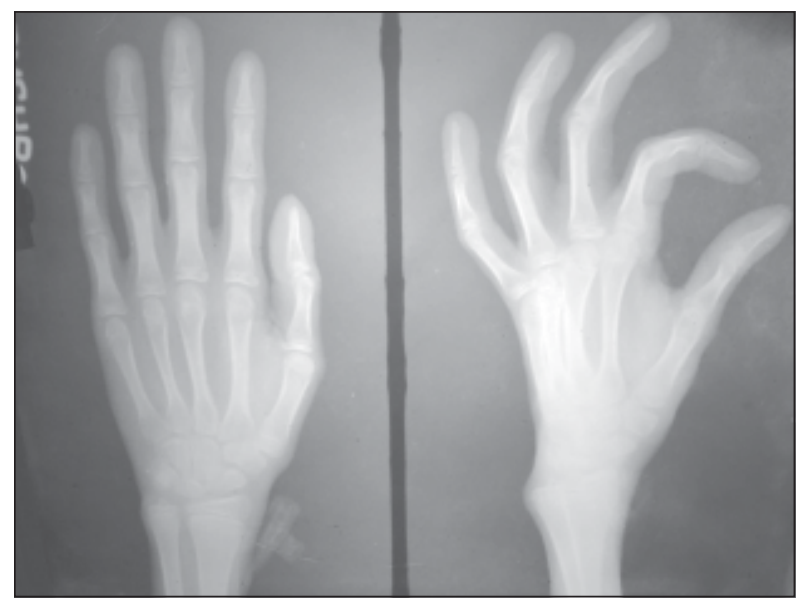

Fig.-9: Long metacarpals and phalanges

Younger sib: The younger sib (Fig.-1) was a male child of 5 years old. His height was $101 \mathrm{~cm}$ and arm span was $107 \mathrm{~cm}$. He had positive wrist and sternberg sign. The child had dextrocardia with single atrium. He has just started developing kyphosis. His limbs and fingers and toes were long and slender. He also developed exertional dyspnoea.

Father: Only the features the father had, was the tall stature, long and slender extremities and fingers and toes. He did not have any other organ anomaly.

\section{Discussion}

Marfan syndrome is a genetic disorder inherited as an autosomal dominant phenotype predominantly involving eye, aorta, heart valves and skeletal system $^{1,2}$. It is a connective tissue disease. It is related to abnormal synthesis of fibrillin-I. Gene locus is situated in the long arm of chromosome $15^{3,4}$. Marfan syndrome is diagnosed mostly based on it's overall presentation. Presentations are added with the advancement of age and maturation. More severely affected subjects present earlier. It may present even in neonate with diminished subcutaneous fat and tall stature resembling failure to thrive. There may be developmental delay due to hypotonia and ligamentous laxity. With the advancement of age thoracic deformity like pectus excavatum and pectus carinatum develops. Cardiac lesion predominantly involves aorta, it's root and valves and the defective aortic media. Aortic dissection occurs due to defect in aortic media ${ }^{5}$. There are reports of subacute infective endocarditis in Marfan syndrome ${ }^{2,5}$. Phornphutkul et al described 36 infants and children with Marfan syndrome and $61 \%$ of them had some form of cardiac anomalies. They found mitral regurgitation is to be the most common (47\%) anomaly and others were, aortic regurgitation, arrhythmias and atrial septal defect ${ }^{6}$. There is a tendency for scoliosis. Increase distensibility of lung parenchyma causes spontaneous pneumo thorax in some cases. There is also dilatation dura ${ }^{3,7}$. Cardiovascular complication so far reported are, aortic root dilatation, dissection of aorta and incompetence of mitral and tricuspid valves. Mitral valve prolapse is progressive and one of the important cause of morbidity in children. These patients may present with arrhythmias, heart failure and endocarditis ${ }^{2,5,6}$. Congenital Contractural Arachnodactyly (CCA) is a condition which simulates Marfan syndrome in respect to the skeletal abnormality. In addition, it has contractures of joints of hands, elbows and knees. Hecht and Beals in their review opined that the case originally described by Marfan was a case of CCA and did not have any cardiac or ocular abnormality which has been found in later described Marfan syndrome $^{1}$. In our patient both of the children satisfies the criteria of Marfan syndrome. Skeletal changes are consistent. Father also shows skeletal morphology consistent with Marfan syndrome. The index patient has situs inversus and endocardial cushion defect which we have not seen any literature. In the same way in the younger sib there was dextrocardia and 
single atrium, which is also not consistent with earlier description of Marfan syndrome. In this family father is minimally affected. But the two sibs are affected in a more severe way. This shows the variability of expression 4 .

\section{References}

1. Hecht F, Beals RK. New syndrome of congenital contructural arachnodactyly described by Marfan in 1896. Pediatrics 1972; 49: 574-79.

2. Goh KL, Hasan Z, Tan CT. Infective endocarditis in Marfan's Syndrome-Acase report. Singapore Medical Journal 1986; 27: 446-49.

3. Robinson LK. Marfan syndrome. In: Behrman
RE, Klieg man RM, Jenson HB, editors. Nelson Text book of Pediatrics. Philadelphia: Saunders; 2004. 2338- 40.

4. Yao Z, Jaeger JC, Ruzzo WL, Morale CZ, Emond $\mathrm{M}$, Francke $\mathrm{U}$, et al. A Marfan syndrome gene expression phenotype in cultured skin fibroblast. BMC Genomics 2007; 8: 319.

5. Mckusick VA. The cardiovascular aspects of Marfan's syndrome: a heritable disorder of connective tissue. Circulation 1955; 11: 321-42.

6. Phornphutkul C, Rosenthal A, Nadas AS. Cardiac manifestation of Marfan syndrome in infancy and childhood. Circulation 1973; 47: 587-96.

7. Marfan syndrome. Medicine Net.com.2009. 